\title{
IMPORTANCE OF LANDSCAPE ELEMENTS IN PERCEPTION OF SPATIAL AESTHETICS IN RESIDENTIAL AREAS
}

\author{
Agnese Sofija Kusmane, Una Īle \\ Latvia University of Agriculture \\ kusmane@googlemail.com; una.ile@1lu.lv
}

\begin{abstract}
Our previous research was focussed on evaluating spaces in the Soviet period housing estates in Riga according to theoretical model of spatial measurements. This model was based on assumption established ex situ that liking and perception of urban space is closely related to buildings. Namely, to the way walls of the buildings shape a setting in terms of its height, width, length. This current paper sets the goal to analyse the impact of landscape elements such as trees, benches, elevations of earth surface, playgrounds on the perception and preference of open spaces in situ. This is done to verify the hypothesis that landscape elements as well as the method of research play a role in our knowledge on how urban spaces are regarded. Semi-structured interviews in walk-along modus are used to talk to inhabitants about the ways they see and like yards and streets in three residential areas: 'Agenskalna priedes', 'Kengarags', 'Zolitude'. The interview materials are analysed discursively. The extracted information is compared to the data previously acquired by using the model of spatial measurements. The results of interviews show that trees are the landscape elements that have the largest impact on how residents perceive the size of a space and how they like a setting. There are also other elements such as benches, playgrounds, elevations that play a role. The interview material displays deviations in preference and perception of the size of space compared to the model of spatial measurements. Yet these deviations can be adapted to the model.
\end{abstract}

Key words: yards, landscape elements, spatial aesthetics, model of spatial measurements.

\section{Introduction}

Our previous work was focussed on classifying open spaces in four Soviet period residential areas in Riga according to four spatial categories, the spaces also were labelled with associated aesthetical values (Kusmane, 2016). This was done according to a model of spatial measurements that was largely informed by environmental psychology and evolutionary aesthetics. Model of spatial measurements is based on the assumption that spatial aesthetics is the shape and proportions (length, width to height ratio, angles of facades etc.) of outdoor spaces as composed by the outer walls of the buildings or sometimes also by the bordering streets. This assumption is also sustained by environmental psychology literature dealing with finding the ideal parameters expressed in meters for the streets and yards (Stamps, 2001; 2005; 2009; Alkhresheh, 2007; Lindal \& Hartig, 2013). A further assumption, which is mirrored in this model, is that among four spatial categories that theoretically cover all the possible spatial shapes and proportions, the open-undefined spaces are most disliked ones. Such spaces are too large, and humans feel endangered here as the next possibility to hide is in a very far distance. Quite disliked are also enclosed scenes, they promote the feeling of extreme enclosure, and also blocked views, which restrict view in one direction. Spaces that fall under spacious, well-structured category are the most liked ones; they provide enough information to learn and sufficient places to hide for humans. This holds evidence not only for the natural, but also for the urban environments (Herzog, 1992). Yet high amount of elements termed mystery and legibility can potentially contribute to higher likability (Nasar
\& Cubucku, 2011). Mystery is a specific type of a prospect that promises new information if one walks into the scene, and legibility is a specific type of refuge promising a hiding place from which a scene can be observed. However, critically should be regarded the fact most but not all knowledge of environmental psychology that the model of spatial measurements is based on, is collected via quantitative surveys ex situ, for instance, by showing photos or computer generated images to respondents and collecting their responses on likability, safety, comfort of the spaces depicted in photos. Also, a critical reconsideration should be awarded to the fact that great many of the environmental psychology researchers when dealing with 'pure' urban spaces are not taking landscape elements into account. For instance, a research investigating urban environments and stress relief correlation asks participants of the experiment to note their reactions in a city centre in order to compare the results with the ones occurring in a city park. The city centre in above mentioned research is an environment, mostly made of concrete and asphalt. Yet, on a closer look acquired via google maps, the particular location in Helsinki possesses few trees that are ignored in the description (Tyrväinen et al., 2014). Ignoring trees as this and other research examples show means that landscape elements as 'minimal' greenery is perceived by scientists as irrelevant. Also, pedestrian ways, benches, pergolas, water features, relief remain overlooked in many cases.

To test the given problems acknowledged above, this research paper is devoted to two questions: to what extent model of spatial measurements that is based on the knowledge acquired ex situ correspond with how 
inhabitants like and perceive the space in situ and whether humans really perceive spaces as bordered by the walls or whether elements of landscape such as greenery, relief etc. have an impact on the way people visually perceive a setting in terms of size, likability and preferability.

The aim of this research is to find evidence that the model of spatial measurements can be enhanced by adding some landscape elements to it. Accordingly, our hypothesis states that such landscape elements as trees, small elevations of earth surface, benches do influence the perception and likability of space as much as the walls of the surrounding buildings do.

\section{Materials and Methods}

Since there is a lot of theoretical knowledge (Herzog, 1992; Stamps, 2001; 2005; 2009; Alkhresheh, 2007; Lindal \& Hartig, 2013) but almost no field research in situ on how individuals perceive and like outdoor urban spaces the most appropriate approach are semi-structured interviews (Stephens, 2010). Semi-structured walk-alongs are more flexible and can be easily adapted to the interview process (Delyser \& Sui, 2012). Such interviews also encourage the partner of the conversation to talk about the spatial experiences that have never been reflected upon (Holton \& Riley, 2014).

The paper utilizes walk-alongs on prechosen roots in four Soviet time housing estates in Riga that were carried out in July, 2014. The interviewees were residents representing broad age, gender and social groups who were randomly met on location and agreed to come along a certain path designed by the researcher. The model of spatial measurements that was already applied in previous research used pre-chosen routes as well. Thus, exactly the same scenes were analysed with the model of spatial measurements and evaluated by inhabitants in order to achieve comparable data sets. For working purposes each scene was ascribed a title consisting of three symbols, for instance, A13. The first symbol corresponds to the first letter of the residential area, which is 'Agenskalna priedes' in this case. The second symbol designates the number of the route - the route No. 1 in this example. The third symbol indicates the number of a scene on that route, which is the third scene in this instance.

After the interviewees had observed the scene, they were asked from the question list. Such questions included: 'How far does the scene go?' 'How often do you visit this scene?' 'How do you like the scene?' 'How could you improve the scene?' Yet since the interviews are of semi-structured type, there were questions asked that did not appear on the question list as well. For example, if the interviewee talked about his or her social background in relationship to likeability of a scene, then the interviewee followed this track in order to acquire unpredicted viewpoint on perception of spatial aesthetics.

The drawbacks of the usage of prechosen routes are that they diminish interviewee's sense of control (Kusenbach, 2003). Human geographer Jon Anderson talks about a demanding style of interviews in general and argues for more partner-like dialogue (Anderson, 2004). We tried to eliminate all the above mentioned downsides. For instance, the speed of the walk and the length of the conversation are defined by the interview.

Collected interview material is deciphered, discursive analyses performed and the narratives of interest, namely, perception and likability, are filtered. The information of liking and perception is applied to according google maps image of the scene be it a yard or a street. These images are later compared to air view images of the same areas that mirror the results acquired by model of spatial measurements earlier.

\section{Results and Discussion \\ The Most Popular Space Shaping Elements}

There are 72 interviews that serve as empirical source of information for this paper. Some of the interviews last as long as $10^{\prime}$, yet some others $-2 \mathrm{~h}$. We analysed 99 scenes (equal number of scenes as when applying the model of spatial measurements). Trees and shrubs appear in the interviews as elements that affect likability and perception many times. Respondents easily explain where in a particular setting trees should be added or removed in order to actually enhance the space. Also, side-roads, benches, skate parks, playgrounds - objects of distinct function prescribed to a certain social group - are responsible for liking or disliking the space. Further, elevations (not more than $5 \mathrm{~m}$ high) also signify for some inhabitants the borders of a space.

A viable comparison of the achieved results to previous results in academic literature is not possible, since to the best of our knowledge, there is no relevant data collected before. There are environmental psychologists who strive to predict the preferability of urban spaces of a certain size and proportions, yet, landscape elements - the focal point of this article are never taken into account (Stamps, 2001; 2005; 2009; Alkhresheh, 2007; Lindal \& Hartig, 2013). There are some authors who try to link preferability of urban space of a certain size to a certain spatial category (Kusmane, 2016), yet also here the landscape elements as part of the aesthetics are ignored. There is a wide agreement among landscape theoreticians that natural elements and good design have a positive effect on perception and appropriation, but the metrical precision regarding the relation of the size of space and design elements is missing (Kaplan, 1995; Foster et al., 2013; Marzbali et al., 2012; Ewing \& Clemente, 2013; Sutton, 2013). Also, academics active in urban 
design theory are in accord when positive effects of natural elements and design elements are regarded (Gehl, 2010; Newman, 1972). Here the metrical data is given, but it is expert and not lay-man based, i.e., no relevance in the context of our paper. In short, there is no research done in comparing theoretically preferred spaces of certain size and content to the spaces and their content in situ.

\section{Trees as Space Shaping Elements}

In the residential area 'Agenskalna priedes' the scene with the working title A11 yard is a trapeze formed by residential buildings measuring $210 \times 140$ $\times 210 \times 90 \mathrm{~m}$, surrounded by houses $14 \mathrm{~m}$ in height. Theoretically i.e. according to the model of spatial measurements this space is ranked as open, undefined space. It possesses some mystery or bended prospects that potentially provide interesting information if one walks into this prospect, but very little legibility or places to hide, and hence is hypothetically evaluated as disliked (Fig. 1). Yet, from the utterances of some inhabitants, it became clear that they are quite satisfied with this yard space. According to some, they perceive trees as a space shaping factor. Trees for them divide the particular yard into at least two smaller spaces in comparison to analysis done by applying the model of spatial measurements. Inhabitants standing at the point A11 reported that the space that they call 'their yard' extends until the group of trees by that implying an area of ca. $70 \times 140 \mathrm{~m}$. This space is less than $1 / 3$ of the original A11.

Figure 1 shows the main groups of trees visible from the standpoint A11 and referred to by interviewees. There are three separate groups of trees on this smaller space that the inhabitants are referring to as 'their yard', and all together they take up ca. $40 \%$ of the space. The largest group in the North consists of 30, 10 of which such as chestnuts (Castanea), maples (Acer), linden (Tilia) trees have low growing branches that one can use for climbing the tree. This cluster is composed of the oldest trees in the area, 5 of them having radius of $0.4 \mathrm{~m}$ and very dense canopies. The group is constantly mentioned in the walk-alongs as the 'trees' that border the yard. There are two smaller patches of trees in this 'space'. Evija, a 38 -year- old female primary school teacher and a young mother who has been living in 'Agenskalna priedes' for 15 years answered to the question how many spaces she saw in the scene A11: 'There are few spaces. Until the trees there is one space. Behind the trees - another one.'Also, other interviewees who commented on this space highlighted the same group in a similar manner. All the quoted inhabitants report that they tolerate the space. It means they indicated certain liking for this setting; however, they also desired some changes in this particular yard. To interpret the new finding back to the model of spatial measurements, the 'new' space measures ca. $70 \times 140 \mathrm{~m}$. These decreased measurements of size (two sides are smaller than 75 $\mathrm{m}$, for more information see Kusmane A.S.) together with now increased mystery and legibility elements, which is obviously added by the presence of denser group of trees with low growing branches (possibility to rescue by climbing, possibility to acquire new information if one walks into the 'forest') allows to define this yard as an open, undefined tolerated space. In short, the space that inhabitants see at the point A11 is much smaller due trees, and at the same time 'tolerable' according to model and also inhabitants.

If we take another scene as an example, not only already existent trees can be described as space shaping elements, but also non-existent trees can be wishfully imagined in those instances where the yard seemed to be too large, both according to the model of spatial measurements in cases of open-undefined spaces, and also according to the utterances of inhabitants. A yard in 'Agenskalna priedes' temporarily called A23 which was previously ranked as open, undefined and disliked yard $(145 \times 55 \times 160 \times 80 \mathrm{~m}$ surrounded by $14 \mathrm{~m}$ high buildings), which with the exception of tree belt along the longer side of the yard $(160 \mathrm{~m})$ and three small trees in the central part of the yard is for $60 \%$ an empty stage. This scene has almost no legibility - possibilities to hide, yet lots of mystery formed by incoming side streets in the background. Residents pronounce disliking of the particular yard.

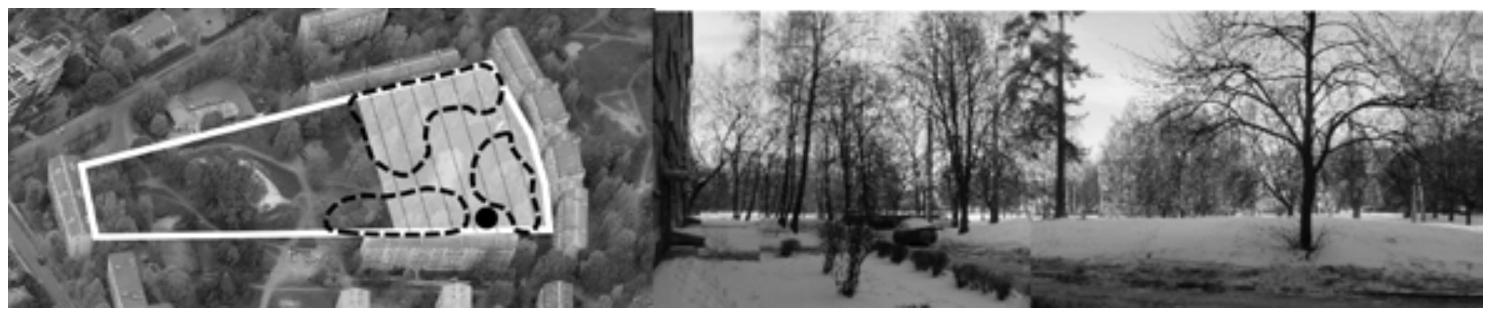

Figure 1. Scene A11. The white contour shows the size of theoretically open, undefined and disliked yard. White transparent field with black lines represents a significantly smaller area 'until the trees' recognized by the inhabitants as 'their yard' and is quite liked. Black torn lines indicate groups of trees visible from stand point of the interview (black point) (modified by authors). 


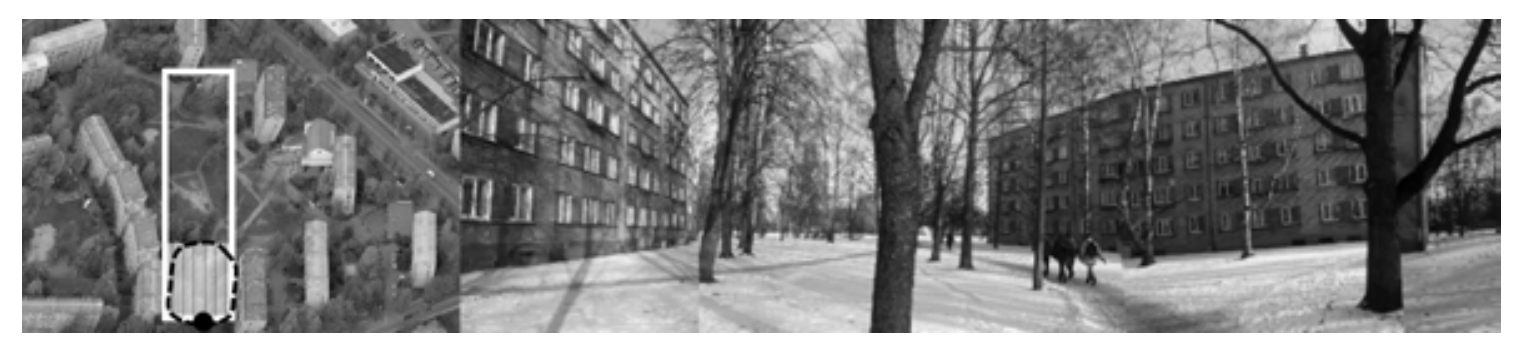

Figure 2. Scene A13. The white contour indicates the area that was, according to the model of spatial measurements, evaluated as an enclosed one. White transparent field with black lines indicates the area 'with trees' reported by the inhabitants as a separate space. Both layers have different sizes: theoretical and reported.

Both scenes, theoretical and reported, are disliked. The black point is the stand point at the time of the interview. Black torn lines indicate group of trees visible from stand points A13 (modified by authors).

Curiously, many answers indicate that more trees would play a major role in enhancing likeability of this otherwise desert like scene. Some residents think that more trees and benches would enhance such a yard, it would become more preferred and used. To interpret this information according to the model of spatial measurements - both trees and benches would provide more hiding space - legibility. Besides that as seen in the previous example, they will contribute to compartmentalizing spaces, and if planted in denser groups, also add some mystery element.

Yet the idea that trees are always a solution for enhancing space is not correct. Inhabitant utterances on other scene that bears a working title A13 show that trees can be irritating. For instance, space that according to the model of spatial measurements is estimated to be $190 \times 36 \mathrm{~m}$ large and surrounded by the buildings of $14 \mathrm{~m}$ is defined as an enclosed scene. Here the mystery counts are very low -1 point, there is no legibility (secondary refuge) in this scene, thus it was evaluated as disliked, see Fig. 2.

All the inhabitants claimed that the space closer to the viewer - the narrow corridor between two buildings is one space, but the meadow behind it is yet another space. Trees play a major role in their answers. The location of trees visible from the standpoint A13 is depicted in the Fig. 2. When Yuta was asked: 'How do you perceive this yard: as one space or as two separate spaces?' She answered: 'This is one [shows to the front area between buildings]. The trees are grown now.' In other words here, too, a respondent indicates that the trees are shaping the space, in this case compartmentalizing it.

The negative feelings in this space A13 that promotes extreme feeling of enclosure were not related to walls, but to extensive greenery. For example, when Santa, a 29 -year- old young working mother, was asked at standpoint A13: 'How does it feel as if there are two kinds of spaces, or one.' She replied: 'Surely two. One is more beautiful, the other one - more grown over, kind of shady.' Thus, also in this instance the model of spatial measurements can be corrected. In this scene, there are exclusively trees with high growing branches only, i.e., no possibility to use the tree as a refuge. Besides that their almost locked-together canopies add to the feeling of enclosure theoretically associated with this space. A similar situation (space that is theoretically defined as enclosed, disliked) where trees with almost no lowgrowing branches make the yard unpreferred by the inhabitants is situated in Kengarags. 20 -year- old Janis who has been living in the residential area for 11 years, in the interview defines trees in this yard as bothersome since they occupy too much space making it too small.

To summarize, the last three given examples on trees, the interviews show that trees as landscape elements do influence the perception of space in terms of its size by compartmentalizing a space or by adding to the feeling of enclosure. The positive effect of the presence of dense groups of trees in open, undefined spaces is that they apparently add to the mystery component (possibility to acquire new information if one walks further into a scene), the presence of trees with low growing branches add to the legibility (a safe hiding place with outlook possibilities). Yet not all trees are seen as enhancement to all kinds of spaces. There is evidence that trees with high growing branches in enclosed spaces make such scenes even more disliked.

\section{Elevations of Earth Surface as Space Shaping Elements}

The other landscape elements appeared in the interviews much less often. However, it can be explained by the fact, that, for example, elevations of earth surface were mentioned only in two scenes in those areas where there was some relief to refer to - 'Agenskalna priedes', 'Zolitude'. For instance, the yard that we already have seen in the examples with trees, now accessed from a different angle has demonstrated, that some inhabitants standing at the viewing point with the working title A41 see mild elevation (ca. $5 \mathrm{~m}$ ) as the border of their yard 


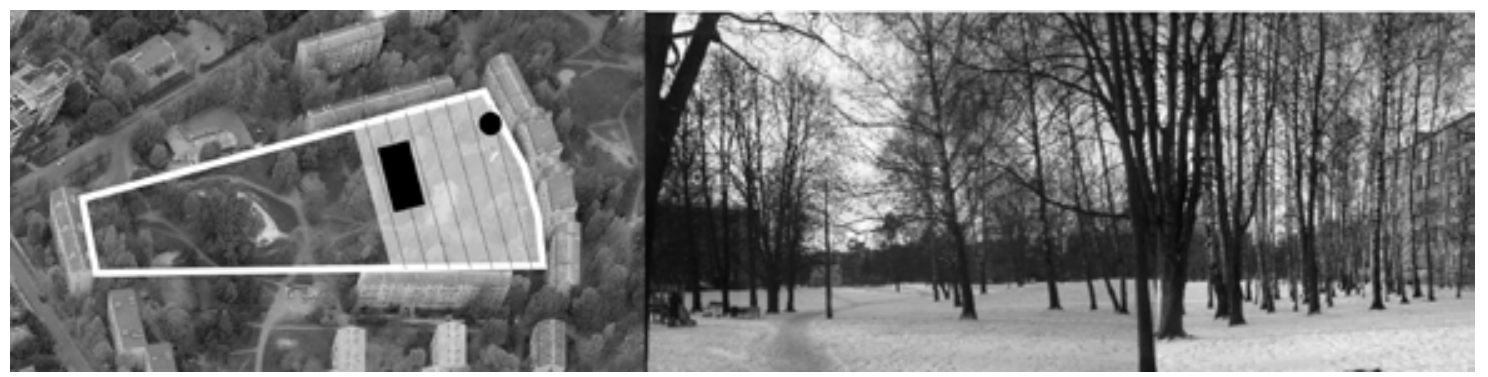

Figure 3. The white contour shows the size of theoretically open, undefined and disliked yard as estimated

by the model of spatial measurements, but the white transparent field with black lines represents a significantly smaller area 'until the elevation' recognized by the inhabitants as 'their yard' and is liked. The black point - position from which the scene A41 is observed by the interviewer and respondent. The black rectangle represents the elevation (modified by authors).

and not the buildings at the furthermost edge of it (Fig. 3). In research this yard A41 (equal to the scene A11, but seen from a different stand point during the interview) is theoretically defined as open, undefined space which, taken into account its low legibility and mystery counts, is disliked. Yet the inhabitants are voicing different opinion. For instance, when 81 years old teacher Irina, who has been living in 'Agenskalna priedes' for 4 years, was asked to explain if the yard, at the border of which we stood, was one space, Irina said: 'One', at the same time pointing to the elevation that boarders off approximately one third of the initial space. Similarly, Laimonis, a 30 -year- old dog owner, who was walking his pet during the interview also had the opinion that place he perceives as his yard ends with the slope of the mentioned elevation. 28 -yearold Sasha chose the elevation as the demarcation of 'his' yard, too.

A surface elevation as the new border 'decreases' the size to approximately $75 \times 140 \mathrm{~m}$. If now the new parameters are translated back into the model of spatial measurements, then the perceived yard due to its decreased size and increased legibility becomes open, undefined and tolerated space. Legibility is increased since inhabitants seemingly perceive the elevation as a safe look-out space from which one can observe the scene but stay safe. 37 years old Sandra, a mother of two youngsters, asked if she would like to see any changes to the yard, answers positively. Sandra would place a pergola on the elevation of earth surface that we see in the yard. 'Moms could sit and observe children. Making sure that all is safe. Children are in the first place.'

In other case, there is a triangle-like yard temporarily called Z21 in 'Zolitude' that measures approximately $200 \times 125 \times 125 \mathrm{~m}$ with $26 \mathrm{~m}$ high buildings surrounding it (Fig. 4). Due to a very small mystery and no legibility counts, it is ranked as open undefined, disliked yard. There are almost no trees, benches or other elements of landscape in the scene, except there is an artificial elevation meant for cycling in the southern part of the space. When looking at this scene, the inhabitants propose more elevation of earth surface to enhance the feeling of likeability. A retired female Valentina asked what would make her feel more like it is actually a yard, has responded that more relief would solve the problem of attachment to this otherwise unliked scene.

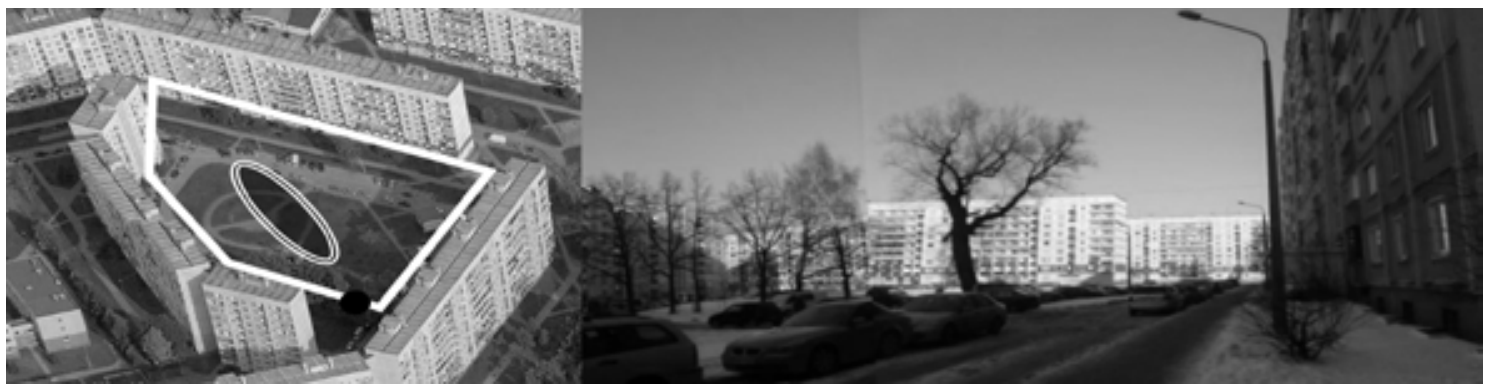

Figure 4. Scene Z21. The white contour represents the open, undefined disliked scene according to the model of spatial measurements. The black point - position from which the scene Z21 is observed by the interviewer and respondent. The black area with a double white line - the imagined elevations of earth surface, which would according to some interviewees enhance the space to become a potentially liked one (modified by authors). 


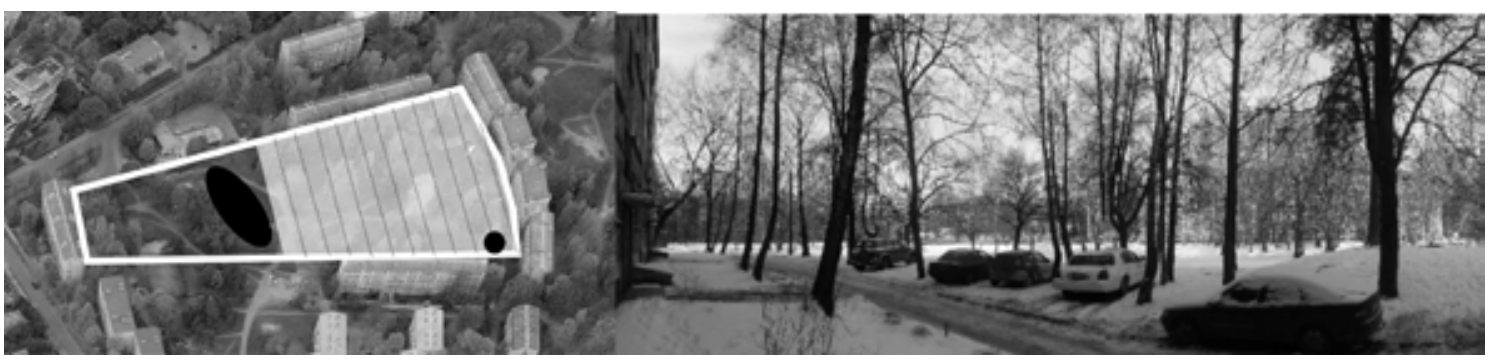

Figure 5. Scene A11. The white contour shows the open, undefined scene as defined by the model of spatial measurements, but the white transparent field with black lines shows the scene as perceived by the inhabitants.

It stretches from the stand point during the interview until the skate park - functional object that for some people dignifies the border of the yard. The 'new' yard is liked by the inhabitants (modified by authors).

Valentina proposed two elevations in the yard, in the front part as well as in the middle of the yards Z21. If one reads her utterance under the premise of environmental psychology, this surface elevation would increase legibility and thus the information quality of the space.

In short, even small elevations (in the examples of case studies $-5 \mathrm{~m}$ ) can be seen as a space compartmentalizing element (case of A41), especially in cases when the space is surrounded by lower buildings $(14 \mathrm{~m})$ that do not outcompete the effect made by the elevation. It seems that in any occasion, elevation plays a role of legibility element which being a refuge adds to the safety feeling.

\section{Functional objects as Space Shaping Elements}

For the purpose of this article we have defined functional objects as those landscape elements that are designed for usage or perceived to be used by a certain social group. For instance, a playground is intended for smaller children, whereas a skate park is for older children. Yet there are also some objects included that can be used by anyone, but perceived to be used by one group only. Benches are the most popular example of it.

Some inhabitants have revealed that their perception of the largeness and preference of space is related to such functional objects. For instance, 29 -year- old Santa, who lives in 'Agenskalna priedes' with her children has commented standing at the point A11 (Fig. 5) that the yard extends until the skate park. She said: 'From here until the skate park' This is where we (Santa has a child) walk most often.' Curiously that also 50 years old Victor, who commented on this yard, standing at the other end of it (as in the scene A51) also mentioned skate park as the border of his yards. 'Everything. The whole peace from that house till the skate park (points to the house Kristapa iela 8).' Thus, the skate park as a border of space must not necessarily include the self-use or use by other members of family to be seen as a significant landscape element that shapes the space.
Both quoted ones implied that they quite liked the space. The new 'border' makes half as large as it was theoretically assumed, now it measures $105 \times 140 \times$ $105 \times 90 \mathrm{~m}$. In this case, it is rather difficult to say if the skate park adds to the mystery or legibility counts since there were no slightest hints on increasing or decreasing these elements after carefully analyzing the above mentioned interviews discursively. To reinterpret the measurements back into the model of spatial measurements, it seems that a space this large $(105 \times 140 \times 105 \times 90 \mathrm{~m})$ is still tolerable. Yet the difficulty is to ascertain, if people who answered in favour of the skate park, also actually perceived groups of trees and elevation as such landscape elements that increase prospects and refuges. More in depth interview would be required to do so. Yet some functional objects such as benches show the most striking metamorphosis of physically visible space.

For instance, an interview with 24 -year- old Martins who has been living in 'Kengarags' whole his life, reveals that the yard that has a working title K13 (Fig. 6) does not exist for him, even though it is situated right outside his window. He explains: 'It is not very well designed. Only drunk people are hanging out on the benches. Nothing happens there.' Martins indicated that benches (a very few pieces of furniture that take a minute part of the space) make this large yard $(60 \times 80 \times 75 \times 90 \mathrm{~m}$, surrounded by houses that are $14 \mathrm{~m}$ in height) avoidable. Theoretically, too, this open, undefined yard that is ranked as disliked because of nonexistent legibility elements (even though there are three elements of mystery). Likewise, 20 -yearold Janis comments on the yard K23 in a relatively similar manner. 'Only alcoholics are there during the night. One cannot sit there'. The yard K13 and K23 have almost identical configuration and conversely - they are alike what regards presence of mystery and legibility elements. Also, retiree Natalija talked about the non-existent yard K23, she prefers walking to Daugava river promenade along the street instead of using a shorter pass along the yard for a similar reason. 


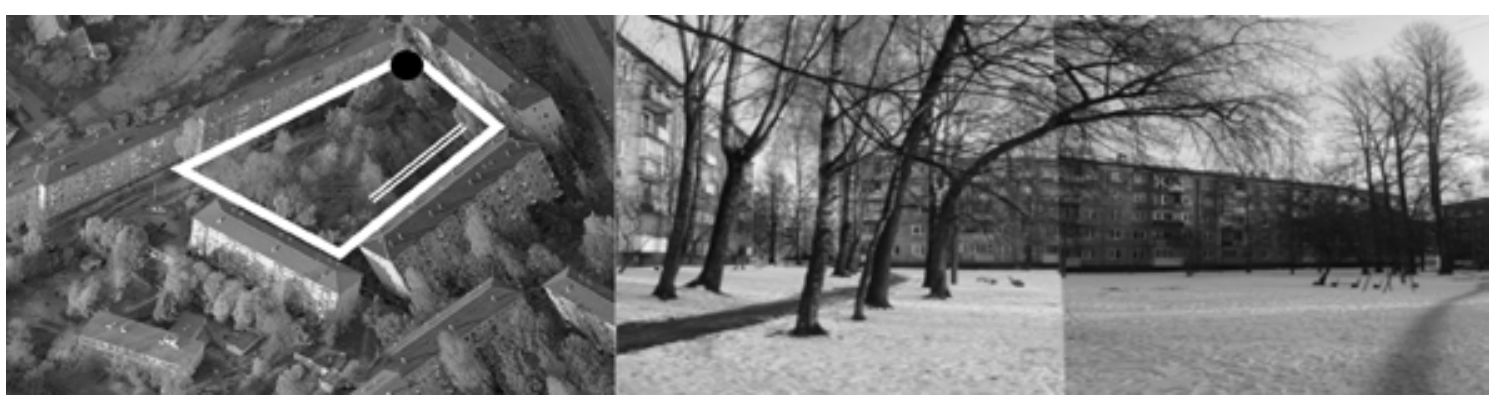

Figure 6. Scene K13. The white contour in figure is ranked as open, undefined disliked according to the model of spatial measurements. Also, inhabitants do not like this space. The black dot marks the stand point during the interview. The double white line marks benches (modified by authors).

In many stories, the smallest landscape element benches symbolize danger - only dangerous people use them. Even though the area of the yard is impressively large $(60 \times 80 \times 75 \times 90 \mathrm{~m})$, a couple of benches at one of its walls completely make the yard disappear form the mental maps. Ironically, the smallest landscape elements become the largest space shaping elements as they are able to out-blend the whole yard. If we translate the given information on this yard back into the model of spatial measurements - a square like space surrounded by almost uninterrupted houses with few mystery elements, then it becomes clear that the lack of legibility (refuge) fuelled by 'dangerous' benches has played a decisive role in dislike of this space.

In short, functional objects such as playgrounds, skate parks, benches, roads are mentioned relatively little, but they all can have either compartmentalizing effect on perceived space size or in some cases completely eliminate certain yards or streets from perception. Importantly, they are seldom mentioned in a way that can be interpreted by researcher as pointing to elements of mystery of legibility. It seems that functional objects often but not always are influencing the perception and the size of space because of their social and not form-shaping ability.

\section{Conclusions}

The development of the model of spatial measurements is far from completed. If the interview material is converted into the language of model of spatial measurements, then the later ones are meaningful addendums to the former one. It means that if environmental psychology concept of walls as space shaping elements is extended towards landscape elements, we might acquire a much more precise tool to predict perception and likeability of any space. To achieve this aim, all the involved landscape elements have to be reinterpreted as legibility or mystery elements as well as new borders of space.

Trees due to their rather frequent mentioning play an extremely important role. The position of branches and grouping of trees, and relationship of number of trees to the size of the space are crucial for positive or negative likeability as well as for increasing or decreasing legibility. Also, small elevations are good enough to compartmentalize a space and make it more likeable because of added mystery and legibility components. Interestingly, the interviews showed that such functional objects as playgrounds and skate parks can demarcate perceived border very effectively whereas functional objects such as benches regardless their small size can erase a space such as a yard from the mental map instantly because of 'dangerous' users associated with them.

\section{References}

1. Alkhresheh, M.M. (2007). Enclosure as a function of height-to-width ratio and scale: its influence on users' sense of comfort and safety in urban street space. Doctor of philosophy university of Florida.

2. Anderson, J. (2004). Talking whilst walking: a geographical archaeology of knowledge. Area, 36, $254-$ 261.

3. Brockington, D., \& Sullivan, S. (2003). Qualitative Research. In Scheyvens, R., \& Storey, D. (eds.). Development Fieldwork: a Practical Guide. London: SAGE.

4. Delyser, D., \& Sui, D. (2012). Crossing the Qualitative-quantitative Divide: Inventive Approaches to Big Data, Mobile Methods, and Rhythm Analysis. Progress in Human Geography, 37, 293 - 305.

5. Ewing, R., \& Clemente, O. (2013). Measuring Urban Design: Metrics for Livable Places. Washington: Island Press.

6. Foster, S., Knuiman, M., Wood, L., \& Giles-Corti, B. (2013). Suburban neighbourhood design: Associations with fear of crime versus perceived crime risk. Journal of Environmental Psychology, 36, 112 - 117. 
7. Gehl, J. (2010). Cities for people, Washington: Island Press.

8. Herzog, T.R. (1992). A Cognitive Analysis of Preference for Urban Spaces. Journal of Environmental Psychology, 12, $237-248$.

9. Holton, M., \& Riley, M. (2014). Talking on the Move: Place-Based Interviewing with Undergraduate Students. Area, 46, $59-65$.

10. Kaplan, S. (1995). The restorative benefits of nature: Toward an integrative framework. Journal of Environmental Psychology, 15, 169 - 182.

11. Kusenbach, M. (2003). Street Phenomenology. The Go-Along as Ethnographic Research Tool. Ethnography, 4, $455-485$.

12. Kusmane, A.S. (2016). How to Measure the Impact of Spatial Aesthetics on the Everyday in the Soviet Housing Estates. Landscape Architecture and Art, 9, 7 - 20.

13. Lindal, P.J., \& Hartig, T. (2013). Architectural variation, building height, and the restorative quality of urban residential streetscapes. Journal of Environmental Psychology, 33, 26 - 36.

14. Marzbali, M.H., Abdullah, A., Razak, N.A., \& Tilaki, M.J.M. (2012). The influence of crime prevention through environmental design on victimisation and fear of crime. Journal of Environmental Psychology, $32,77-88$.

15. Nasar, J.L., \& Cubucku, E. (2011). Evaluative Appraisals of Environmental Mystery and Surprise. Environment and Behavior, 43, 387 - 414.

16. Newman, O. (1972). Defensible Space. Crime Prevention Through Urban Design.Chicago: Macmillan.

17. Stamps, A.E. (2001). Evaluating Enclosure in Urban Sites. Landscape and Urban Planning, 57, 25 - 42.

18. Stamps, A.E. (2005). Enclosure and Safety in Urban Spaces. Environment and Behavior, 37, 102 - 132.

19. Stamps, A.E. (2009). On shape and spaciousness. Environment and Behavior, 41, 526 - 548.

20. Sutton, R. (2013). Ecology of Scale in Visual Landscape Assessments University of Nebraska-Lincoln. Retrieved February 20, 2017, from: http://digitalcommons.unl.edu/arch_land_facultyschol/17.

21. Tyrväinen, L., Ojala, A., Korpela, K., Tsunetsugu, Y., \& Kagawa, T. (2014). The influence of urban green environments on stress relief measures: a field experiment. Journal of Environmental Psychology, 38, $1-9$. 